\title{
Using men as community-based distributors of condoms
}

Cynthia P. Green

Stephanie Joyce

Population Council

James R. Foreit

Population Council

Follow this and additional works at: https://knowledgecommons.popcouncil.org/departments_sbsr-rh

Part of the Demography, Population, and Ecology Commons, International Public Health Commons, and the Public Health Education and Promotion Commons How does access to this work benefit you? Let us know!

\section{Recommended Citation}

Green, Cynthia P., Stephanie Joyce, and James R. Foreit. 2002. "Using men as community-based distributors of condoms," FRONTIERS Program Brief. Washington, DC: Population Council. 


\section{Using Men as Community-based Distributors of Condoms}

T heHIV/AIDS epidemic has led program managers to seek approaches to family planning (FP) that will also help combat HIV/AIDS and other sexually transmitted infections (STIS). These approaches include use of simplified STI diagnosis and treatment protocols and promotion of male and female condoms. One aspect of condom promotion that is receiving increased attention is the idea of adding men to communitybased distribution (CBD) programs in order to increase the use of condoms as dual protection against STIs and pregnancy.

Dual protection refers to protection from STIs, including HIV/AIDS, and pregnancy. Methods of dual protection consist of: (1) use of a male or female condom alone, (2) use of a condom plus another contraceptive method, (3) abstinence, (4) nonpenetrative sex, and (4) mutual monogamy between uninfected partners plus use of a contraceptive method. The male latex condom is the only contraceptive method that, when used correctly and consistently, provides protection against STIS, including HIV/AIDS. (The effectiveness of the female condom and nonlatex condoms is not yet sufficiently documented) (Spieler et al. 2001). Currently, an estimated 6 to 9 billion male condoms are used worldwide annually. However, experts estimate that 24 billion male condoms should be used annually in order to provide adequate protection against

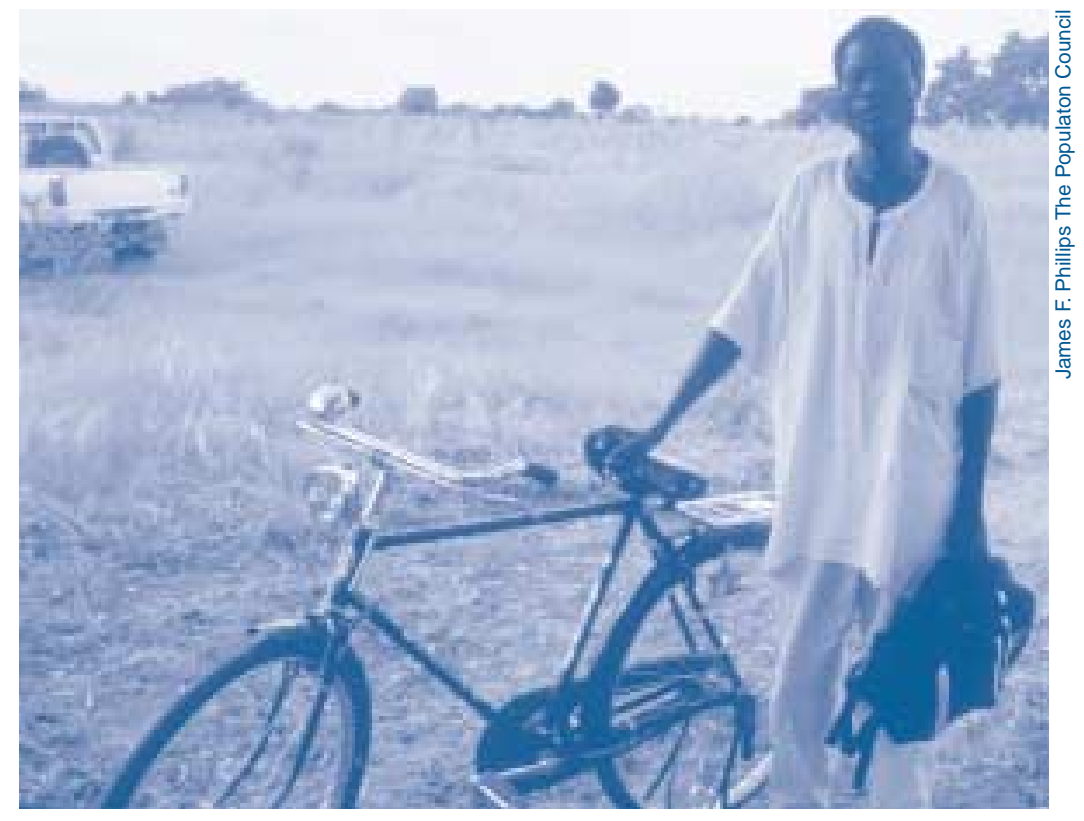

STIs and HIV/AIDS (Gardner et al. 1999). Increased use of men as CBD agents could help to fill this "condom gap."

\section{CBD programs are important} sources of temporary FP methods in many countries, but most programs distribute far fewer condoms than oral contraceptives. One reason for the preponderance of female methods may be that most CBD agents are women. Evidence suggests that the most successful CBD agents are those who share the same characteristics as their target populations, while the least successful are those who differ greatly from the target group (Repetto 1977). Thus, gender differences between distributors and potential clients may limit the sale of condoms. CBD programs might be more successful if they included both men and women as distributors.
This Program Brief reviews evidence from operations research and other studies in 13 countries about the effectiveness of men as CBD workers. It addresses five basic issues that influence whether or not recruiting more men as CBD workers will result in greater use of male condoms as dual protection against pregnancy and STIs:

\section{Do communities accept men as CBD distributors?}

\section{Do men sell more condoms} than women do?

\section{Do men recruit more male clients than women do?}

\section{Do male agents distribute as} many coupleyears of contraceptive protection (CYP) as female agents do?

\section{Must program managers take special steps to incorporate men into CBD programs?}




\section{Do Communities Accept Men as CBD Distributors?}

If men as CBD agents are to make an impact on dual protection (or any other reproductive health outcome), they must be acceptable to community leaders and potential consumers alike. The evidence shows that clients and communities accept men as CBD agents and welcome the information and services that they provide. Some studies that demonstrate this acceptability are:

- Cameroon. In a 1991-93 quasiexperimental study, the Ministry of Public Health trained 69 male opinion leaders in a conservative rural community as CBD agents. Their duties included: education on FP; sale of condoms, spermicides, and oral rehydration solution; and referral to FP clinics. A survey of 1,360 men and women one year after the intervention found that knowledge of modern contraceptive methods increased significantly (see Figure 1). Four in five villagers surveyed said that they approved of the male $\mathrm{CBD}$ agents. The reasons cited by

$\begin{array}{lr}\text { Men as CBDs } \\ \text { Contents } \\ \text { Acceptability } & 2 \\ \text { Productivity } & 4 \\ \text { Client Recruitment } & 6 \\ \text { CYP Distributed } & 7 \\ \text { Program Issues } & 8 \\ \text { Conclusions } & 9 \\ \text { References } & 10\end{array}$

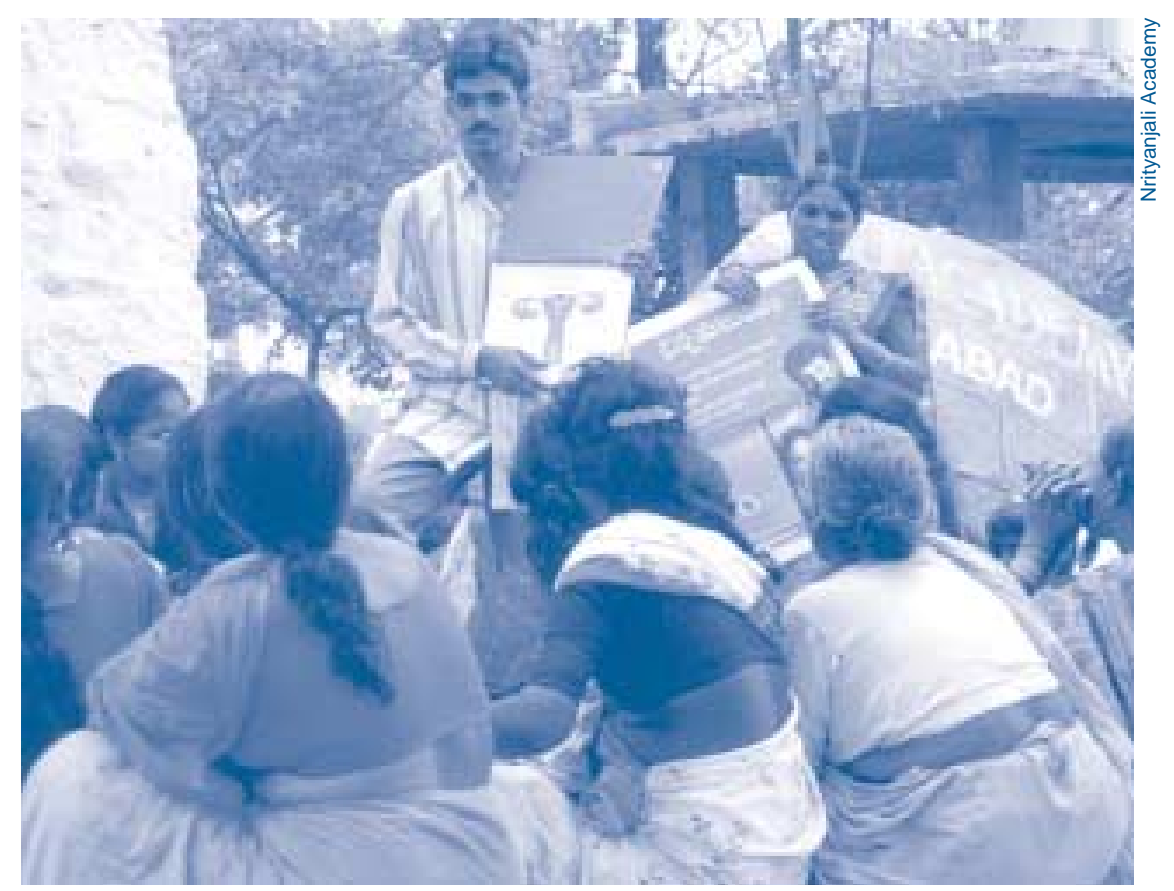

the small proportion of villagers who expressed disapproval $(6 \%$ of women and $4 \%$ of men) were: "women can do it better" and "both men and women should do it" (Awasum et al. 1993, p. 48).

Kenya. To test the feasibility of using traditional health practitioners in rural villages, the African Medical and Research Foundation (AMREF) trained 50 male herbalists and 50 female traditional birth attendants (TBAs) to provide FP services in two rural districts. Villagers of both genders accepted the herbalists as well as the TBAs (Nyamwaya et al. 1993).

In some settings the introduction of male agents may initially cause controversy because of cultural views on gender roles and other factors. For example, focus group participants in a study in Kenya's Kilifi district expressed some reservations about home visits by male CBD workers:

\section{Figure 1. Impact of Male Opinion Leaders, Cameroon}

Percent Who Can Name at Least One Modern Contraceptive Method

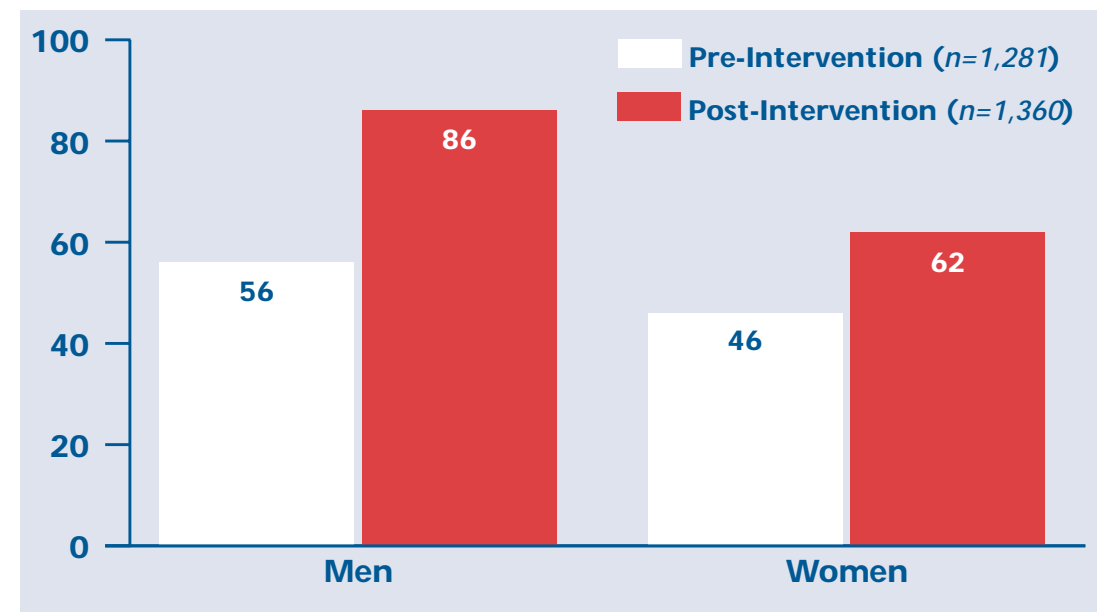

Source: Awasum et al. 1993. 
"It is good to have only women CBDs and not men because of jealousies."

"Male agents can misbehave with other people's wives."

(FPAK and PC 1995:11-12).

A CBD program assessment in Tanzania found that men in some areas initially did not want male CBD agents providing services to their wives, but after some education they changed their views. Conversely, CBD agents

\section{Educating Men about Health}

Community members in Kenya stated that male distributors could be helpful in educating men about health issues:

"One spouse might know about FP but another doesn't. If CBD agents go to homes, they're able to teach spouses on family planning-especially men-and CBD agents are able to refer clients for attention concerning other diseases."

"They help the timid women to counsel their husbands by talking about family planning to men, and reinforcing the counseling provided to women in $\mathrm{MCH} / \mathrm{FP}$ clinics."

“CBD agents ... have also taught men to appreciate immunization and [child] nutrition."

-Community members, Kenya (FPAK and PC 1995:11) reported that some clients prefer to receive FP services from members of the opposite sex (Chege et al. 1998).

Many program planners assert that men may be the only viable alternative for introducing family planning in maledominated societies where women's influence and movements outside the home are restricted. In settings where discussions of sexuality are taboo between the sexes, male agents are needed to educate men on dual protection and other reproductive heal th issues. Reports from Ghana, Mali, and Pakistan show that men can be successful in such traditional societies.

Ghana. Male community workers in Navrongo, Ghana helped to promote discussion of family planning among village elders and helped to ensure support for female community nurses (Phillips et al. 1999; Population Council and Ghana Ministry of Health 1999).

Mali. CBD projects in two rural districts demonstrated that male community health agents can be effective in educating male community members through group talks and home visits, and in providing contraceptive supplies (Kak and Signer 1993; Katz et al. 1998). Mali's national CBD program, begun in 1990, uses equal numbers of male and female agents (Doumbia et al. 1999).

\section{Frontiers in Reproductive Health Program Brief No. 2}

\author{
Authors: Cynthia P. Green, Ph.D., \\ Stephanie Joyce, and \\ James R. Foreit, Dr. P.H.
}

Design: Vincent Hughes Visualization

The assistance of the following reviewers is appreciated: Ian Askew, Nicole Buono, Sarah Harbison, Marjorie Hom, Diana Prieto, and John Townsend.

Photos on pages $1,2,6,7$, and 8 were selected from M/MC Photoshare, at www.jhuccp.org/mmc

Suggested citation: Cynthia P. Green, Stephanie Joyce, and James R. Foreit. 2001. "Using Men as Communitybased Distributors of Condoms." Program Briefs. 2. Washington, D.C.: Population Council/FRONTIERS.

Frontiers in Reproductive Health Population Council

4301 Connecticut Ave., N.W.

Suite 280

Washington, D.C. 20008

U.S.A.

Tel.: $\quad 202-237-9400$

Fax: 202-237-8410

E-mail: frontiers@pcdc.org www.popcouncil.org

This publication was made possible through support provided by the Office of Population, Bureau for Global Programs, Field Support and Research, U.S. AGENCY FOR INTERNATIONAL DEVELOPMENT (USAID), under the terms of Cooperative Agreement No. HRN-A-00-98-00012-00. The opinions expressed herein do not necessarily reflect the views of USAID.

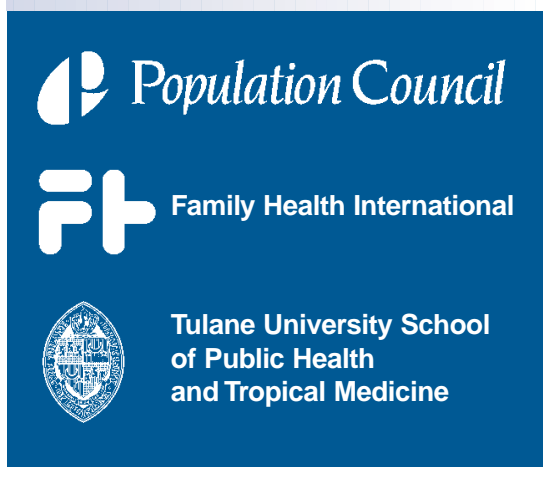


- Pakistan. A cadre of male-only community educators targeted husbands during the inital stages of a program to promote awareness, discussion, and acceptance of family planning methods. Despite fears of a conservative backlash in this traditional sociey, men in the community were very receptive. In the first three months of the project, the 100 male community educators distributed more than 13,000 condoms (Kamal and Fowler 1991; Population Reference Bureau 1993).

\section{Lesson learned:}

Almost all evidence reviewed suggests that communities accept men as CBD distributors.

\section{Performance of Male CBD Agents: Evidence from Experiments}

Around the world, the vast majority of CBD distributors are women, reflecting the historical emphasis of FP programs on female clients. While there are numerous examples of communities' acceptance of men as CBD agents, program managers also need evidence that men can be effective as distributors of condoms. This evidence requires data from experimental studies such as operations research.

A literature search of documents identified only three controlled operations research studies that specifically compare the performance of male and female distributors. The studies were conducted in Kenya (Family Planning Association of Kenya and Population Council 1995), Peru (Foreit et al. 1992), and Congo (formerly Zaire; Bertrand et al . 1993) and use prospective, quasiexperimental designs.

\section{Do Male Agents Distribute More Condoms than Women Do?}

Increasing dual protection implies increasing the number of condoms distributed. Therefore a program manager needs to know if adding men to the cadre of women distributors will really increase condom distribution. Two of the three experimental studies compared male and female CBD agents regarding the type of contraceptive method that they distributed.

Peru. The study in Peru compared male and female agents in two CBD programs operating in different cities. Male distributors in both programs sold significantly more condoms per month

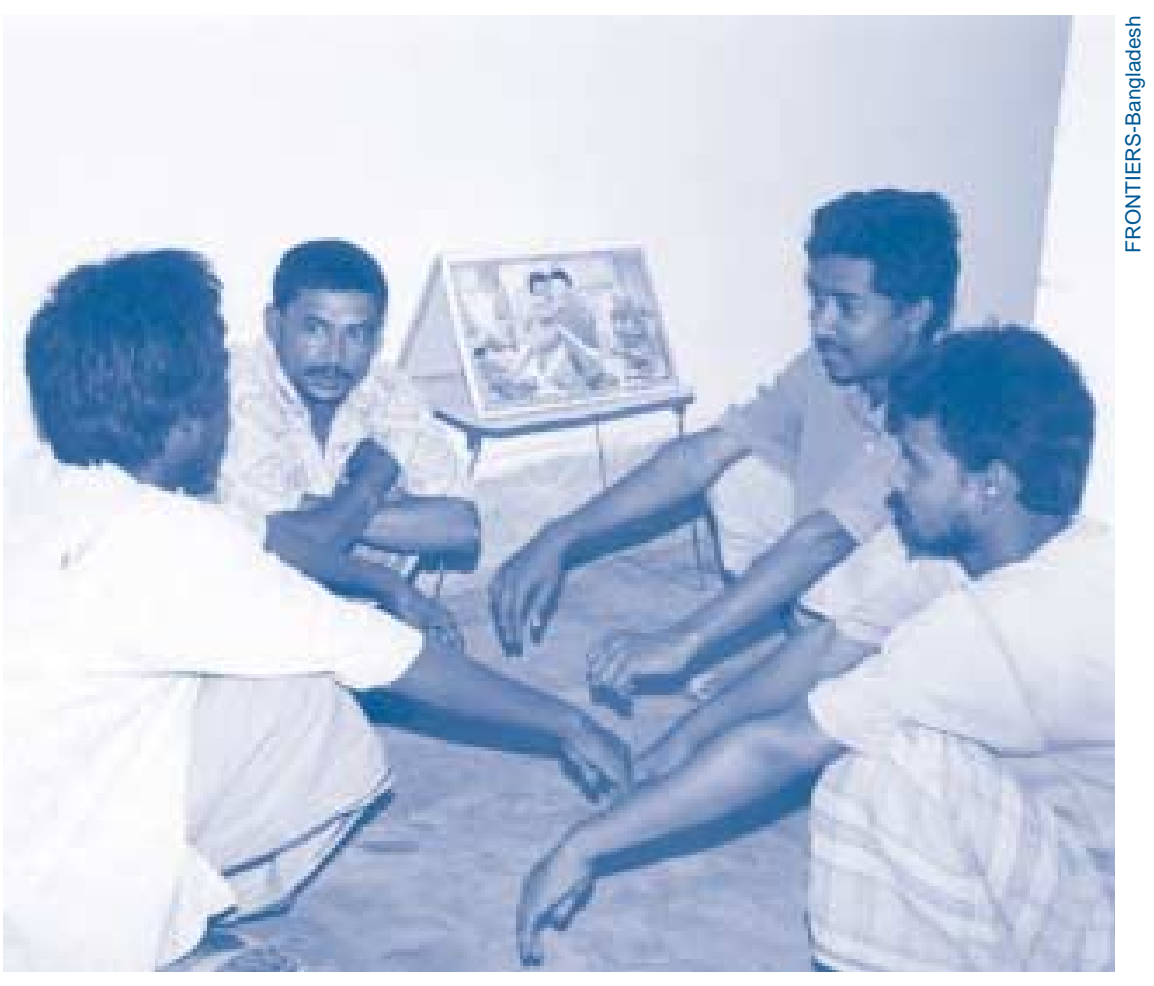


than female distributors. In the PROFAMILIA CBD program located in the capital, Lima, 38 male distributors sold a median of 49 condoms per month, compared with 24 for 171 female distributors. In the CENPROF CBD program in the northern city of Trujillo, 52 male distributors sold a median of 162 condoms per month, compared with a median of 88 for 94 female distributors (see Figure 2; Foreit et al. 1992).

Kenya. The study in the Kilifi district of Coast Province, Kenya found that male volunteers distributed almost three times more condoms than did female volunteers. The 15 male volunteers distributed a mean of 9,550 condoms per agent during the 18-month study period, while the 15 female volunteers distributed a mean of 3,523 condoms per agent (FPAK and PC 1995).

Two other studies that used service records to compare the productivity of male and female CBD agents in Tanzania (Chege et al. 1998) and Zimbabwe (Maggwa et al. 2001) found that men and women distributed roughly the same quantities of condoms, but these studies did not control for possible confounding factors such as the agent's age, location, or length of time in the program.

\section{Lesson learned:}

The two controlled experimental studies support the hypothesis that adding male distributors to CBD programs will increase condom distribution.

\section{Why Are Experiments Important?}

Experiments are vital for improving programs because they allow comparison between groups under controlled conditions. However, comparing men's performance with women's is complex.

It is important to note that male and female agents differ systematically on many factors besides gender (education, occupation, marital status, length of time in the program, training, and location of the CBD post). These confounding factors, rather than gender per se, may be responsible for any observed differences in performance. Therefore, this review will emphasize the results of studies that address at least some of the potential confounding variables in comparing male and female CBD worker performance.

The Kenya study controls for the CBD worker's geographic location and duration in the program. The Peru and Congo (formerly Zaire) studies control for these factors as well as demographic factors such as the CBD worker's marital status and education.

\section{Figure 2. Condoms Distributed by CBD Agents, Peru}

Median Number Distributed Monthly

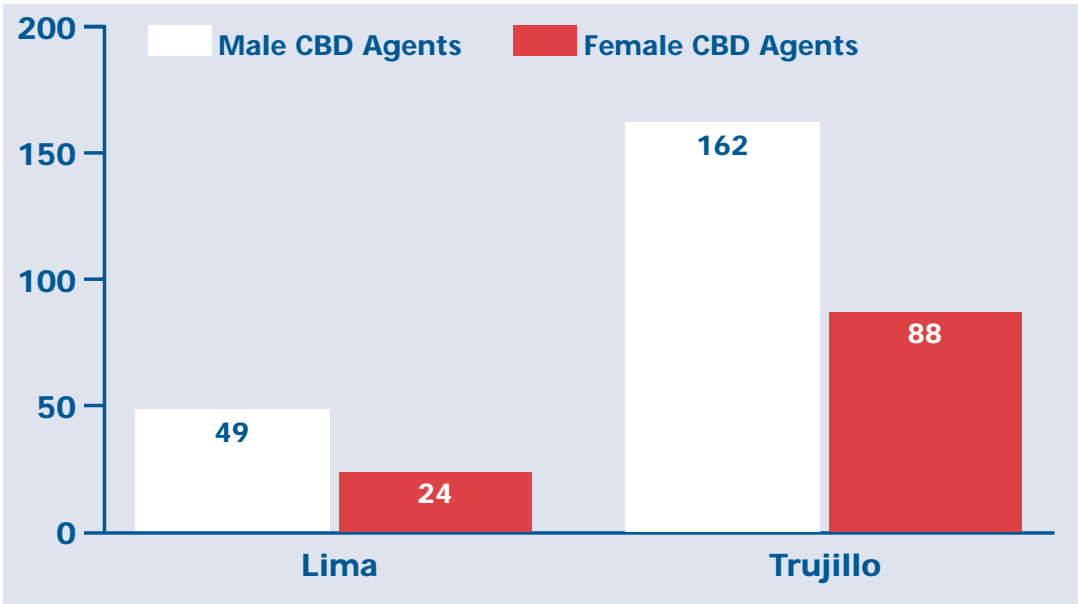

Source: Foreit et al. 1992.

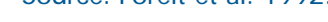


Figure 3. Client Gender, Peru

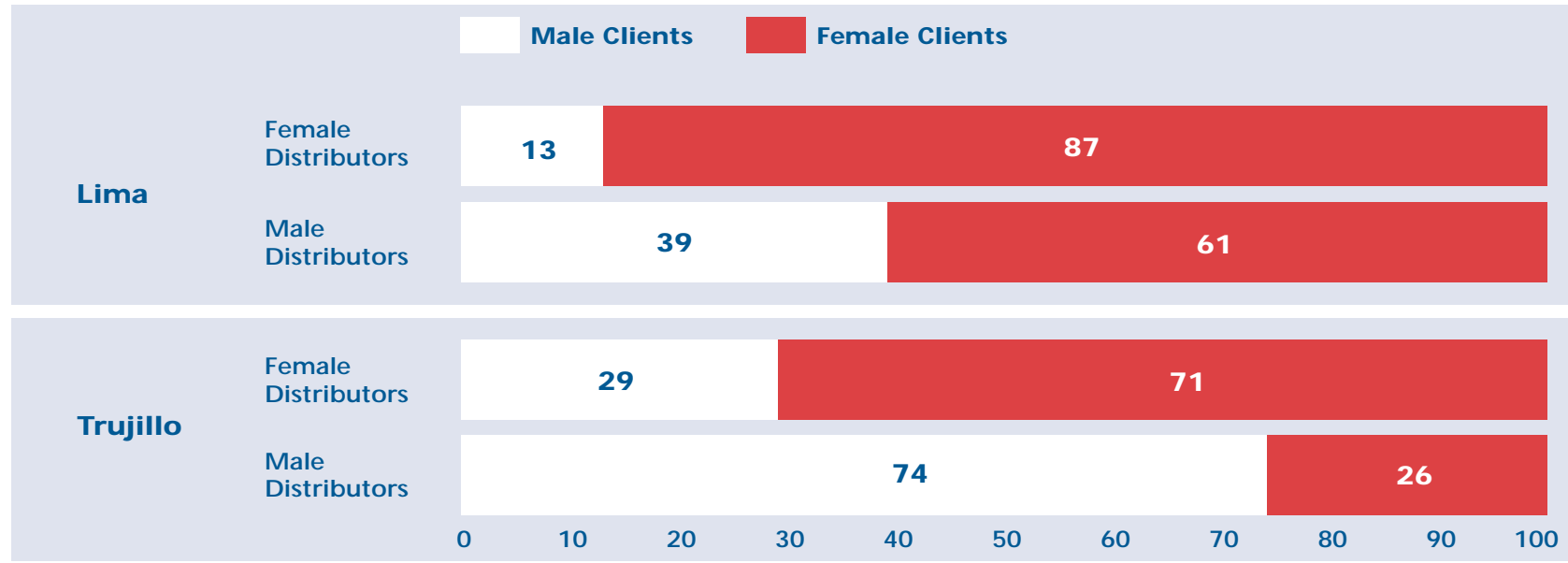

Source: Foreit et al. 1992.

3. Do Male Agents Recruit More Male Clients?

Increased dual protection through the use of male condoms implies that CBD programs

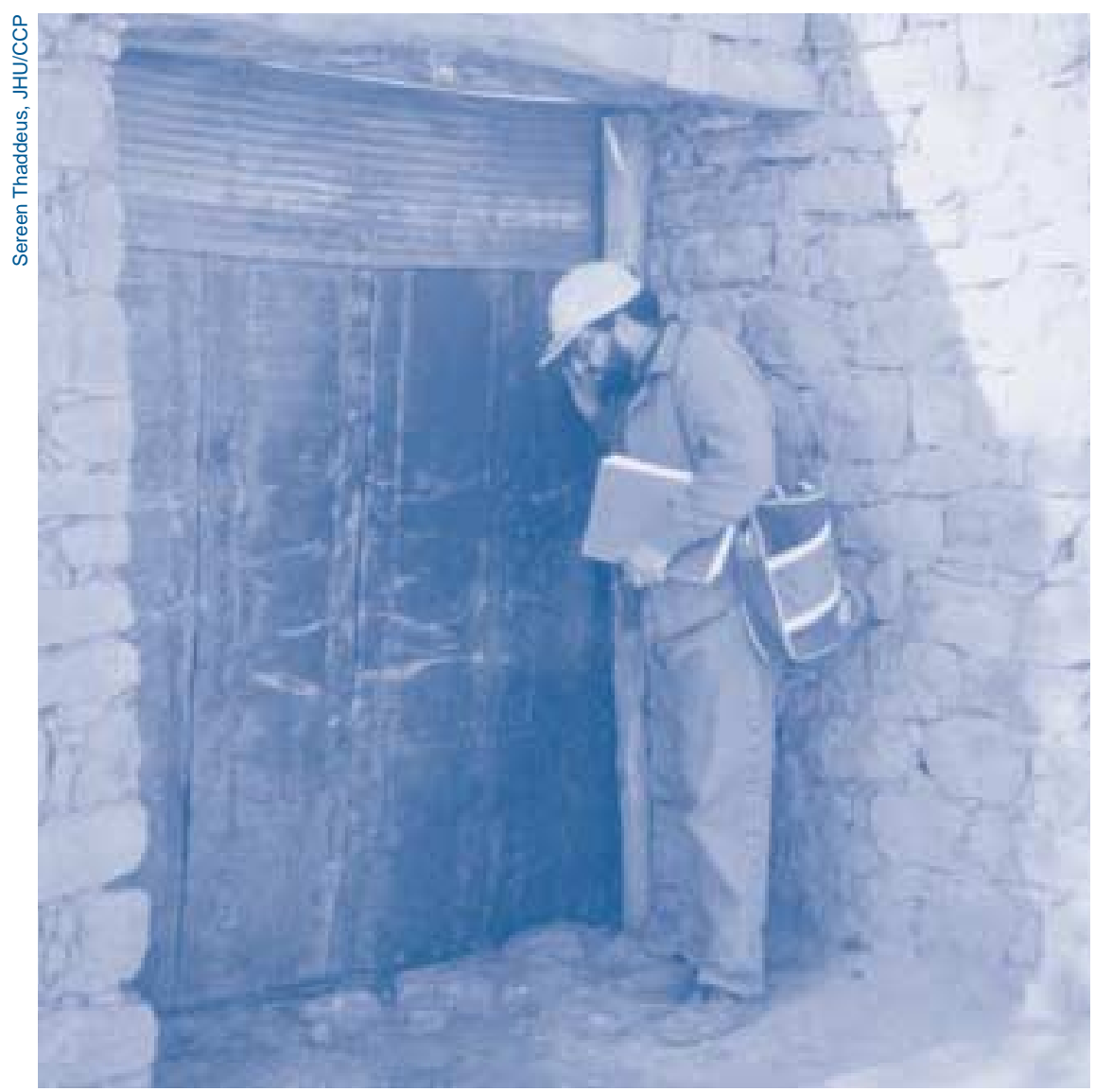

must recruit more men as clients. Of the three experimental studies, only the Peru study (Foreit et al. 1992) examined the effect of CBD agent gender on client more pronounced in Trujillo, gender. The differences were

\section{Lesson learned:}

The single study available suggests that male distributors serve more male clients and female distributors serve more female clients. 


\section{Do Men Distribute Less Contraceptive Protection than Women Do?}

For a program, ben eficial increases in condom distribution stemming from the recruitment of men might be offset by lower overall distribution of contraception. All three experimental studies examined total contraceptive output using couple years of protection (CYP):

Congo. In the PRODEF study in rural Bas Zaire, no significant difference in mean monthly CYP was found by CBD agent gender when controlling for location, age, education, and marital status (Bertrand et al. 1993).

- Peru. In the Peru study, there was no significant difference in median monthly CYP distributed by men and women in Lima; but in Trujillo men distributed significantly more CYP per month than women did (2.8 versus 1.8 ) (Foreit et al. 1992).

Kenya. In Kilifi, Kenya, male CBD agents distributed more than twice as much CYP as female agents did-an average of 277 CYP during the 18-month study, compared with women's average of 130 CYP (FPAK and PC 1995).

Other uncontrolled studies indicate a mixed picture regarding the relative productivity of male versus female distributors. Two studies found no significant difference between male and female agents:

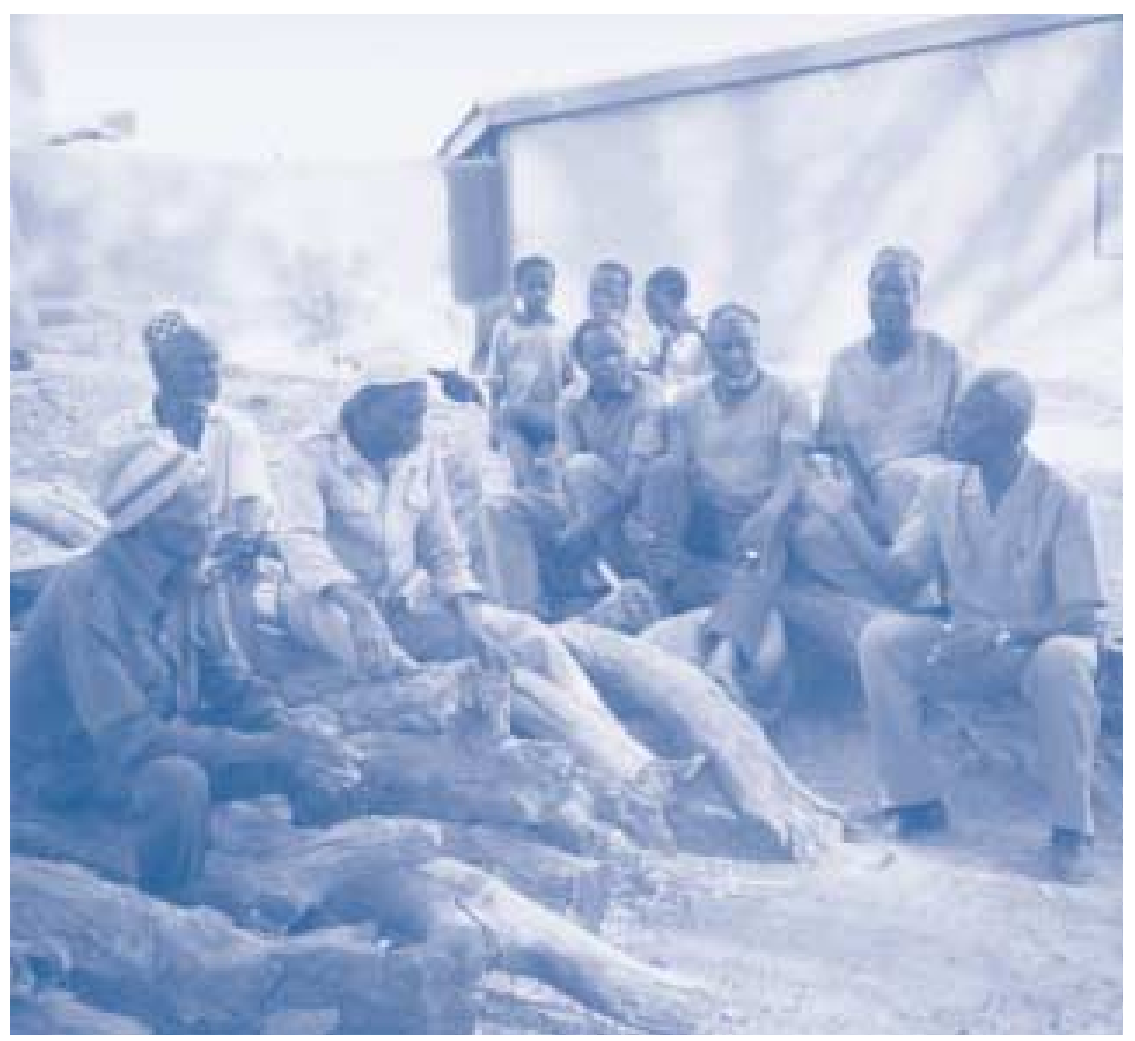

Paraguay. An analysis of the CBD program of the Paraguayan Center for Population Studies found that male distributors provided more CYP than female distributors did, but the difference was not statistically significant (Melián et al. 1989).

Kenya. An assessment of public and private CBD programs in Kenya identified eight sites in which male and female agents worked under similar conditions. In five of the eight sites, male agents provided the same or higher average CYP than did female agents, although the differences were not statistically significant (Chege and Askew 1997).

In contrast, assessments of CBD programs in Tanzania and Zimbabwe reported that female distributors provided more CYP than males did, mainly due to greater pill distribution (Chege et al. 1998; Maggwa et al. 2001).
Overall, the evidence suggests that men distribute as much total contraceptive protection as women. Studies show that the total output of CBD agents is mostly influenced by programmatic factors other than gender, such as distribution location, supervision, and promotional support as well as some personal characteristics such as age and occupation (Bertrand et al. 1981; Bertrand et al. 1993; Melián et al. 1989).

\section{Lesson learned:}

In most settings, men and women are equally productive as CBD distributors. 


\section{Does Adding Male Distributors Involve Special Challenges?}

Although most available studies that involve male CBD agents focus on output and productivity, they also discuss issues of concern to managers wishing to incorporate men into CBD programs. These issues-managers' prejudices, recruitment, and training-are discussed in the following sections.

Managers' prejudices. Negative perceptions by male and female program managers and supervisors may limit the participation and effectiveness of men in CBD programs. Female managers may be hostile to the idea of adding men to what they see as a women's health program. In the Peru study, where CBD supervisors were mostly women, they were resistant to recruiting men as CBD agents, explaining that:

"It is easier for women to talk to women."

"Men have less free time to do the work."

"Men produce less."

The supervisors also expressed concerns about the ability of male agents to keep records and turn in monthly reports. "Men only want to sell contraceptives. They don't want to give talks and keep records," stated one supervisor (Foreit et al. 1992:60). In practice, however, men were

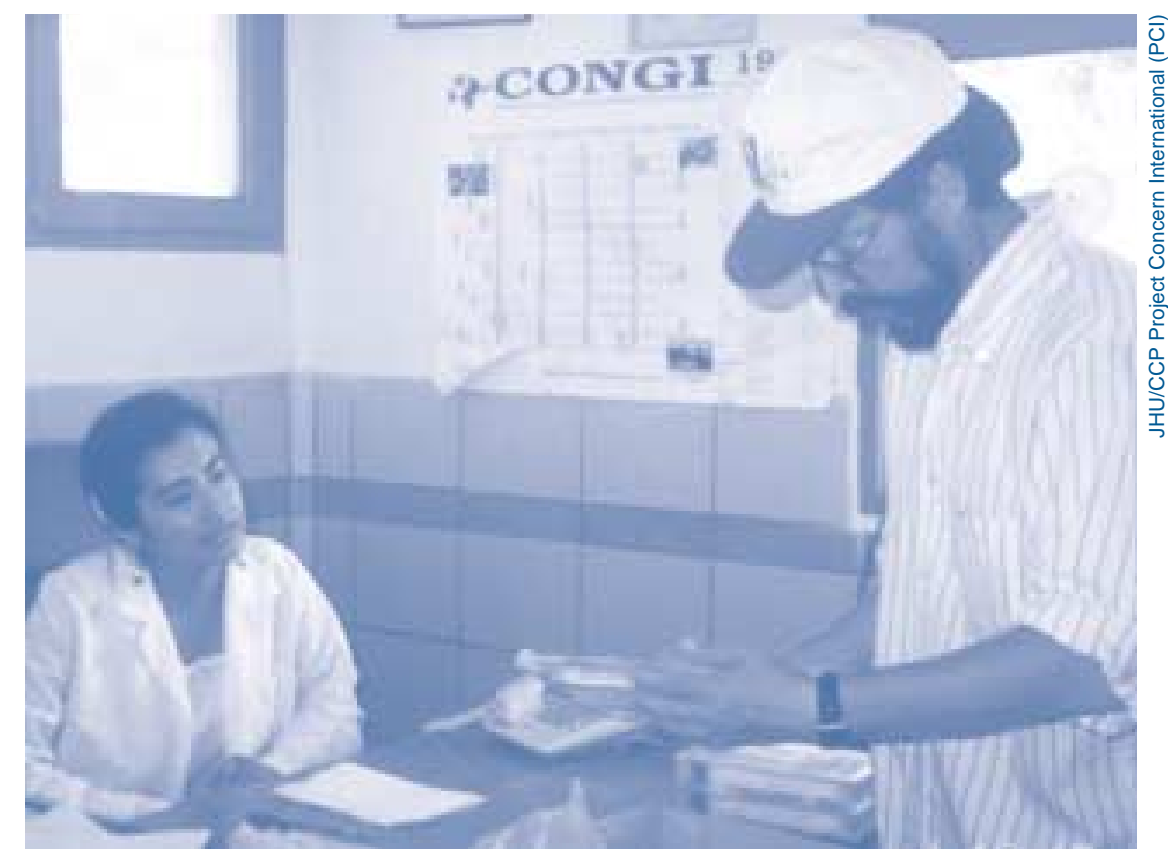

as good as women in recordkeeping. Neverthel ess, despite the success of men in the PROFAMILIA program, the female supervisory staff never fully accepted men as distributors. When men left through attrition, they were replaced with women (Foreit et al. 1992).

\section{Lesson learned:}

Program leaders should be prepared to address the reluctance of managers and supervisors to recruit men as distributors.
Recruitment. Programs may need to use different strategies to recruit men. In some settings, program managers have reported that men are harder to recruit than women. Men often have full-time jobs or other work that limits their availability to CBD programs. For example, in the Peru study, PROFAMILIA and CENPROF found it difficult and time-consuming to recruit men (Foreit et al. 1992). On the other hand, in Kilifi, Kenya, program workers thought that it might be easier to recruit men as distributors. Their rationale was that men, especially those who are unemployed, may have more time to devote to CBD work than do women, who have a heavy workload at home (FPAK and PC 1995).

\section{Lesson learned:}

Recruitment problems vary greatly by location. Better documentation of recruitment procedures and studies focused on effective recruitment of men are needed. 
Training. Descriptions of male CBD programs generally do not report difficulties in training men. In most developing countries, training male $C B D$ agents may be easier (and thus perhaps more cost-effective) than training women because the men are more likely to be literate.

Assumptions that training regimens need to be changed for men are often found to be incorrect. For example, in the Kenya study, focus group participants had said that the male herbalists and female traditional birth attendants would not want to be trained together. However, joint training sessions in two sites were "extremely successful, with each group learning from the other." The researchers reported that male herbalists were easier to train as CBD workers than the women were. The women "required a much longer period before being able to pass their evaluation exams, receive their diplomas, and enter the intervention stage of the study" (Nyamwaya et al. 1993:10). In Peru, men and women were also trained together without difficulty.

Nevertheless, men's work schedules may require some changes in scheduling. For example, in the Peru study of CBD agents, training had to be scheduled on weekends to accommodate the men's work schedules (Foreit et al. 1992).

\section{Conclusions}

Men appear to have great potential in increasing the distribution of male condoms, thus providing dual protection, through CBD programs. Men have been shown to be acceptable as distributors in countries as diverse as Kenya, Pakistan, and Peru. The key arguments in favor of adding men to programs are that: (1) men distribute more condoms than women do; (2) men also appear to serve more male clients; and (3) concerns about low productivity by men in the overall distribution of contraceptives are unjustified. In all controlled studies male agents distributed equal or greater amounts of CYP than women agents distributed.

In adding men to CBD programs, managers and supervisors may have to address prejudices of program staff against men as distributors. In some places they may find men relatively hard to recruit, compared with women. However, once recruited, men and women can be trained together.

Finally, increasing men's involvement in CBD programs may yield broader benefits to reproductive health and rights. By specifically reaching out to men in the community, male CBD agents may help to increase men's acceptance of family planning and may result in men and women sharing responsibility for contraception more equally. By making more condoms available, male CBD agents can increase the acceptability and use of condoms for dual protection, thus contributing to the reproductive well-being and overall health of communities. The inclusion of male distributors in CBD programs should be considered an element of best practices.

\section{Lesson learned:}

Men and women can be trained together. In some situations, the timing of the training may have to be adjusted to fit varied work schedules. 


\section{References}

Awasum, David Neba et al. 1993. Promotion and Delivery of Family Planning Services in the Donga Mantung: An Operations Research Study on the Role of Male Opinion Leaders in Rural Cameroon. Yaounde: Ministry of Public Health, Cameroon and Dakar: Population Council Africa OR/TA Project.

Bertrand, Jane T. et al. 1980. "Characteristics of Successful Distributors in the Communitybased Distribution of Contraceptives in Ghana." Studies in Family Planning 11(9/10):274-285.

Bertrand, Jane T. et al. 1981. "Evaluation of Contraceptive Knowledge of Community-based Distributors in Guatemala." International Family Planning Perspectives 7(4):136-140.

Bertrand, Jane T. et al. 1993. "Community-based Distribution of Contraceptives in Zaire." International Family Planning Perspectives 19(3):84-91.

Chege, Jane et al. 1998. Factors Affecting the Outputs and Costs of Community-based Distribution of Family Planning Services in Tanzania. Nairobi: Population Council.

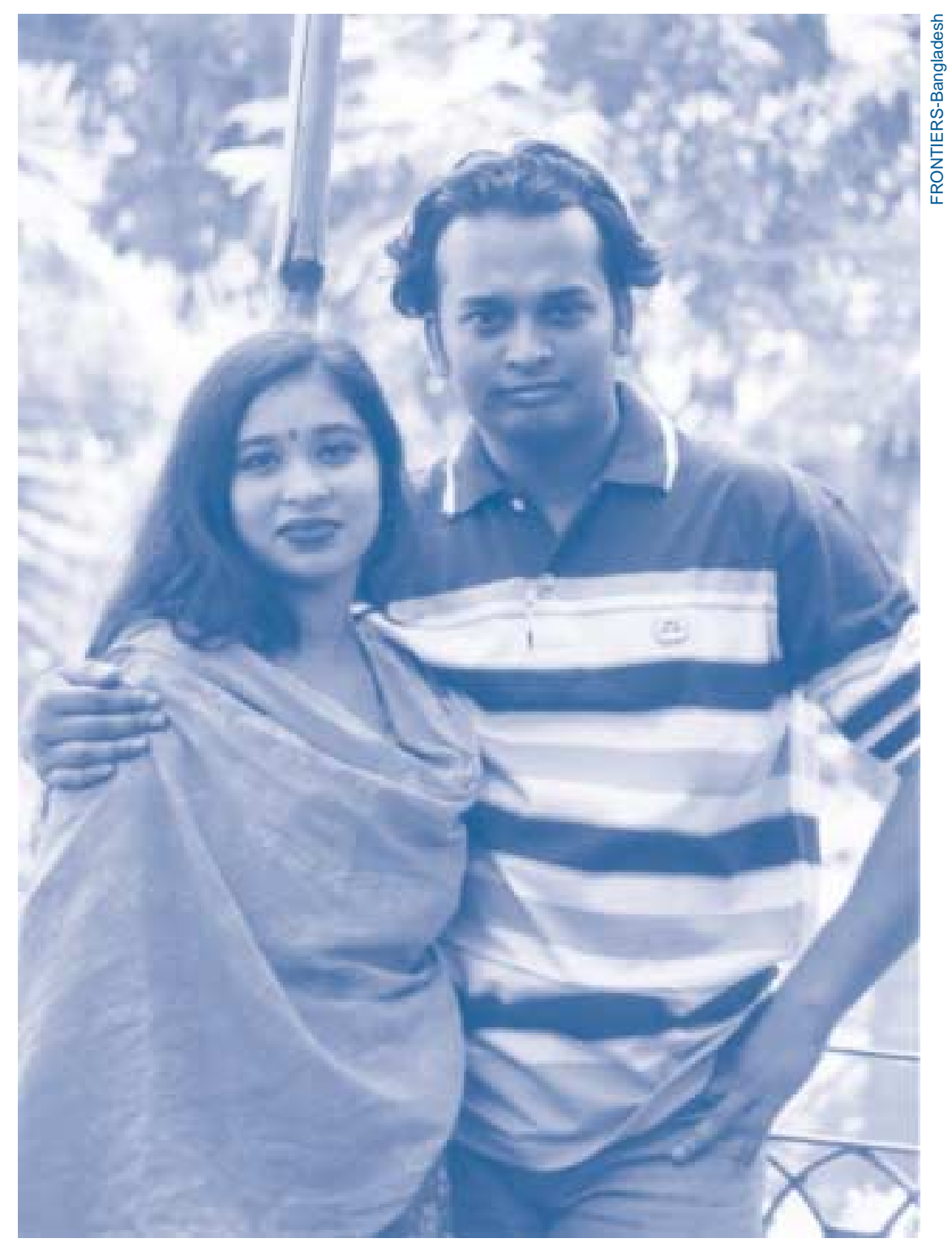

Chege, Jane and Ian Askew. 1997. An Assessment of Community-based Family Planning Programmes in Kenya. Nairobi: Population Council/Africa OR/TA.

Doumbia, Seydou, Mamadou Djiré, and Amadou Traoré. 1999. Etude d'evaluation finale du project de distribution à base communautaire des contraceptifs au Mali. Bamako, Mali: Population Council.
Family Planning Association of Kenya (FPAK) and Population Council (PC)/Africa OR/TA Project. 1995. Increasing Male Involvement in the Family Planning Association of Kenya (FPAK) Family Planning Program. Nairobi: Population Council. 
Foreit, James R. et al. 1992. "A Comparison of the Performance of Male and Female CBD

Distributors in Peru." Studies in Family Planning 23(1):58-62.

Gardner, Robert, Richard D. Blackburn, and Ushma D. Upadhyay. 1999. "Closing the Condom Gap." Population Reports Series H, No. 9. Baltimore: Johns Hopkins University School of Public Health.

Kak, Lily P. and Marjorie Brahms Signer. 1993. "The Introduction of Communitybased Family Planning Services in Rural Mali: The Katibougou Family Health Project." Working Paper No. 2. Washington, D.C.: Centre for Development and Population Activities.

Kamal, Imtiaz and Christina Fowler. 1991. "Community Organization Implements Successful Male Involvement Project in Northwest Frontier Province, Pakistan." Paper presented at the 119th Meeting of the American Public Health Association, Atlanta, Georgia, November 11-14.

Katz, Karen R. et al. 1998. "Increasing Access to Family Planning Services in Rural Mali through Community-based Distribution." International Family Planning Perspectives 24(3):104-110, September.
Maggwa, Baker Ndugga et al . 2001. An Assessment of the Zimbabwe National Family Planning Council's Community Based Distribution Programme. Nairobi: Population Council/FRONTIERS.

Melián, M., J.M. Carrón, R. Vernon, and J. García-Núñez. 1989. In Search of a Rural Family Planning Service Delivery Model in Paraguay: Final Technical Report. Asunción, Paraguay: Centro Paraguayo de Estudios de Población and the Population Council/INOPAL.

Nyamwaya, David et al. 1993.

Expanding Family Planning Delivery Systems Using Traditional Health Practitioners: An Operations Research Study in Rural Kenya. Nairobi: African Medical and Research Foundation (AMREF) and Population Council Africa OR/TA Project.

Phillips, James. F., Wendy L. Green, and Elizabeth F. Jackson. 1999. "Lessons from Community-based Distribution of Family Planning in Africa." W orking Papers No. 121. New York: Population Council.
Population Council and Ghana Ministry of Health. 1999. The Navrongo Community Health and Family Planning Project: Lessons Learned 1994-98. Navrongo, Ghana: Population Council.

Population Reference Bureau. 1993. "Pakistan: Family Planning with Male Involvement Project of Mardan." Brochure.

Repetto, Robert. 1977.

"Correlatives of Field-worker Performance in the Indonesian Family Planning Program: A Test of the Homophily Heterophily Hypothesis." Studies in Family Planning 8(1):19-21.

Spieler, Jeff, Mihira Karra, and Kirsten Vogelsong. 2001.

"Condom Promotion and Dual Protection." Paper presented at the USAID Open Forum on Condom Promotion and Dual Protection, Washington, D.C., February 21, 2001. 


\section{Program Brief No. 2}

Frontiers in Reproductive Health Population Council 4301 Connecticut Ave., N.W.

Suite 280

Washington, D.C. 20008

U.S.A.

Tel.: $\quad 202-237-9400$

Fax: $\quad 202-237-8410$

E-mail: frontiers@pcdc.org www.popcouncil.org

This publication was made possible through support provided by the Office of Population, Bureau for Global Programs, Field Support and Research, U.S. AGENCY FOR INTERNATIONAL DEVELOPMENT (USAID), under the terms of Cooperative Agreement No. HRN-A-00-98-00012-00.

The opinions expressed herein do not necessarily reflect the views of USAID. 